This work was supported by the U.S. Public Health Service (Grants CA-02978 and GM-5TOI-26) and by Hoffmann-La Roche Inc. We thank Dr W. E. Scott for gifts of labelled 2,3-dehydroemetine.

Bray, G. A. (1960). Analyt. Biochem. 1, 279.

Jondorf, W. R., Simon, D. C. \& Avnimelech, M. (1966). Molec. Pharmac. 2, 506.

Randerath, K. (1966). Thin-Layer Chromatography, p. 92. New York: Academic Press Inc.

Robinson, D., Smith, J. N. \& Williams, R. T. (1953). Biochem. J. 53, 125.

Schwartz, D. E. \& Herrero, J. (1965). Am. J. trop. Med. $14,78$.

The Absorption, Excretion and Metabolism of Disodium $\left[{ }^{14} \mathrm{G}\right]$ Cromoglycate in Man

By S. R. Walker, A. J. Richards and J. W. Paterson. (Asthma Research Council Clinical Pharmacology Unit, Institute of Diseases of the Chest, Brompton, London S.W.3, U.K.)

Disodium cromoglycate, the disodium salt of 1,3 - bis - (2 - carboxychromon - 5 - yloxy) - 2 - hydroxypropane, is used in the treatment of bronchial asthma (Howell \& Altounyan, 1967; Kennedy, 1967).

After the oral administration of disodium $\left[{ }^{3} \mathrm{H}\right]$ cromoglycate to monkeys, rabbits and rats, $1 \%, 2 \%$ and $4 \%$ of the dose was absorbed respectively (G. F. Moss, personal communication). However, intratracheal administration in these three species indicated that disodium cromoglycate was quickly absorbed from the lung (Moss, Jones, Ritchie \& Cox, 1970). Intravenous studies (G. F. Moss, personal communication) have shown that this compound is rapidly excreted via the bile and urine in several animal species. Chromatography of bile and urine indicated that all the recovered radioactivity was in unchanged disodium cromoglycate.

The fate of inhaled disodium $\left[{ }^{14} \mathrm{C}\right]$ cromoglycate has been examined in asthmatic patients. Maximum plasma concentrations $(9 \mathrm{ng} / \mathrm{ml})$ were obtained within $15 \mathrm{~min}$ of inhaling the disodium cromoglycate $(20 \mathrm{mg}, 33 \mu \mathrm{Ci})$, and the half-life in plasma was $81 \mathrm{~min}$. The urinary-excretion findings suggest that drug reaching the lung is rapidly absorbed and excreted. Only $2 \%$ of the inhaled dose appeared in the $24 \mathrm{~h}$ urine, $84 \%$ being recovered in the faeces.

The fate of orally administered disodium $\left[{ }^{14} \mathrm{C}\right]$ cromoglycate $(20 \mathrm{mg}, 8 \mu \mathrm{Ci})$ was examined. The drug was poorly absorbed from the gastrointestinal tract, only $0.4 \%$ of the dose appearing in the $24 \mathrm{~h}$ urine and $82 \%$ being recovered from the faeces. No metabolites were detected chromatographically.
The intravenous administration of disodium $\left[{ }^{14} \mathrm{C}\right]$ cromoglycate $(4 \mathrm{mg}, 6 \mu \mathrm{Ci})$ resulted in approximately equal amounts being excreted in the urine and the faeces. Disodium cromoglycate is highly polar with a molecular weight of 512, and thus satisfies the criteria for biliary excretion (Millburn, Smith \& Williams, 1967).

A comparison of our results with the animal data shows that the monkey handles the drug in a similar manner to man.

The work was supported by a grant from the Medical Research Council.

Howell, J. B. L. \& Altounyan, R. E. C. (1967). Lancet, ii, 539.

Kennedy, M. C. S. (1967). Acta allerg. 22, 487.

Millburn, P., Smith, R. L. \& Williams, R. T. (1967). Biochem. J. 105, 1283.

Moss, G. F., Jones, K. M., Ritchie, J. T. \& Cox, J. S. G. (1970). Toxic. appl. Pharmac. 17, 691.

\section{The Fate of $\left.{ }^{3} \mathrm{H}\right]$ Salbutamol in Man}

By M. E. Evans, A. J. Richards, S. R. Walker and J. W. Paterson. (Asthma Research Council Clinical Pharmacology Unit, Institute of Diseases of the Chest, Brompton, London S.W.3, U.K.)

The catecholamine isoprenaline is an adrenergic $\beta$-receptor stimulant. It affects both bronchial smooth muscle and cardiac muscle. It has been widely used by inhalation in the treatment of asthma, its main disadvantages being its short duration of action and cardiac stimulation. The metabolic fate has been examined in man (Morgan et al. 1969).

Salbutamol [2-tert.-butylamino-1-(4-hydroxy-3. hydroxymethyl)phenylethanol] is a non-catechol adrenergic $\beta$-receptor stimulant. Its advantages over isoprenaline are longer duration of action, selective action on bronchial smooth muscle and the fact that it can be taken orally.

The metabolism and excretion of $\left[{ }^{3} \mathrm{H}\right]$ salbutamol has been investigated in rat, rabbit, dog and guinea pig (L. E. Martin, personal communication). In these species between 50 and $80 \%$ of the dose was excreted in the urine $(0-48 \mathrm{~h})$. The $O$-glucuronide (4-phenyl) of salbutamol was identified as the major metabolite in the urine of rat, rabbit and guinea pig. The dog excreted four unidentified minor metabolites in addition to salbutamol.

The fate of orally administered $\left[{ }^{3} \mathrm{H}\right]$ salbutamol (4 $\mathrm{mg}$ or $8 \mathrm{mg}$ ) has been studied in asthmatic patients. Maximum plasma concentrations (0.23 or $0.43 \mu \mathrm{M}$ ) were obtained 2.5-3 h after dosing. The half-life in plasma was $3.5 \mathrm{~h}$. Analysis of plasma samples indicated that $80 \%$ of the radioactivity 
was in a metabolite, as yet unidentified, the remainder being unchanged salbutamol. The urinaryexcretion findings showed that the drug was well absorbed, $80 \%$ of the dose appearing in the urine $(0-72 \mathrm{~h})$ and $6 \%$ in the faeces. Unchanged salbutamol accounted for $40 \%$ of urinary radioactivity, $60 \%$ consisting of the same metabolite as that found in plasma.

Administration of $\left[{ }^{3} \mathrm{H}\right]$ salbutamol by aerosol resulted in a similar metabolic pattern in the plasma and urine of patients receiving the drug. The metabolite is an acid-labile compound that is not hydrolysed by $\beta$-glucuronidase or arylsulphatase. Investigations so far have shown this metabolite to be unique to man.

This work was supported by a grant from the Medical Research Council.

Morgan, C. D., Sandler, M., Davies, D. S., Conolly, M. E., Paterson, J. W. \& Dollery, C. T. (1969). Biochem. J. 114, 8 P.

\section{Formation of Epoxides as Microsomal Meta- bolites of Polycyclic Hydrocarbons}

By P. Srms, A. Hewer and P. L. Grover. (Chester Beatty Research Institute, Institute of Cancer Research: Royal Cancer Hospital, Fulham Road, London SW3 6JB, U.K.)

Microsomal metabolism of polycyclic hydrocarbons in vitro leads to the formation of reactive intermediates (Grover \& Sims, 1968; Gelboin, 1969) that could be epoxides. Evidence supporting the suggestion (Boyland, 1950) that epoxides are intermediates in the microsomal hydroxylation of double bonds has been obtained with benzene and naphthalene (Jerina, Daly, Witkop, Zaltzman-Nirenberg \& Udenfriend, 1968, 1970) and with phenanthrene and dibenz $[a, h]$ anthracene (Pandov \& Sims, 1970). Synthetic 'K-region' epoxides of polycyclic hydrocarbons are active alkylating agents that react with nucleic acid either in vitro (Grover \& Sims, 1970 ) or in cells in culture (Grover, Forrester \& Sims, $1971 a)$. In view of the activity of such epoxides in transforming rodent cells in culture (Grover et al. 1971b), it seemed important to establish the formation of epoxides as intermediates in the metabolism of polycyclic hydrocarbons.

In the present work ${ }^{3} \mathrm{H}$-labelled samples of phenanthrene, benz $[a]$ anthracene and dibenz $[a, h]$. anthracene have been incubated with rat liver microsomal fraction fortified with an NADPHgenerating system. After incubation, non-polar products were extracted into ether, the appropriate carrier 'K-region' epoxide was added, the ether was removed by evaporation and the residue was chromatographed on an alumina column. Fractions containing the radioactive peak that was eluted with the carrier epoxide were pooled and evaporated to dryness, and the epoxide, together with a further addition of unlabelled carrier epoxide, was crystallized from cyclohexane. Radioactively labelled ' $K$-region' epoxides obtained in this way have been crystallized to constant specific radioactivity and the associated radioactivity has been shown to be convertible $(a)$ by treatment with methanolic hydrochloric acid into products that possess on thin-layer chromatograms the chromatographic properties of phenols, (b) by incubation with microsomal epoxide hydrase, in the absence of cofactors, into products that possess on thin-layer chromatograms the chromatographic properties of dihydrodiols and (c) by heating with GSH in aqueous acetone at alkaline $\mathrm{pH}$ into water-soluble products that possess the paper-chromatographic properties of acid-labile glutathione conjugates. In addition, the only 'non-K-region' epoxide prepared to date, benz [a]anthracene 8,9-epoxide, has characteristics (P. Sims, unpublished work) that readily distinguish it from the 'K-region' derivative used in these studies. The role of epoxides in the biological effects produced by polycyclic hydrocarbons, which include carcinogenesis, is currently under investigation.

Boyland, E. (1950). Biochem. Soc. Symp. 5, 40.

Gelboin, H. V. (1969). Cancer Res. 29, 1272.

Grover, P. L., Forrester, J. A. \& Sims, P. (1971a). Biochem. Pharmac. (in the Press).

Grover, P. L. \& Sims, P. (1968). Biochem.J. 110, 159.

Grover, P. L. \& Sims, P. (1970). Biochem. Pharmac. 19, 2251.

Grover, P. L., Sims, P., Huberman, E., Kuroki, T., Marquardt, H. \& Heidelberger, C. (1971b). Proc. natn. Acad. Sci. U.S.A. (in the Press).

Jerina, D. M., Daly, J. W., Witkop, B., ZaltzmanNirenberg, P. \& Udenfriend, S. (1968). Archs Biochem. Biophys. 128, 176.

Jerina, D. M., Daly, J. W., Witkop, B., ZaltzmanNirenberg, P. \& Udenfriend, S. (1970). Biockemistry, Easton, 9, 147.

Pandov, H. \& Sims, P. (1970). Biochem. Pharmac. 19, 299.

Enzymic Formation of $\beta$-D-Monoglucuronide, $\beta$-D-Monoglucoside and Mixtures of $\beta-D-$ Monoxyloside and $\beta$-D-Dixyloside of Bilirubin by Microsomal Preparations from Rat Liver

By K. P. M. Heirwegh, J. A. T. P. MeuwisseN and J. Fevery. (Liver Physiopathology Laboratory, Rega Institute, University of Leuven, B-3000 Leuven, Belgium)

Glucosyl transfer from UDP-glucose to several steroids by microsomal preparations from rabbit liver has been demonstrated by Collins, Williamson 